\title{
Leucine-rich $\alpha$-2-glycoprotein is a marker for idiopathic normal pressure hydrocephalus
}

\author{
Madoka Nakajima • Masakazu Miyajima • Ikuko Ogino • Maki Watanabe • \\ Haruko Miyata $\cdot$ Kostadin L. Karagiozov • Hajime Arai - Yoshiaki Hagiwara • \\ Tatsuya Segawa $\cdot$ Kyoko Kobayashi $\cdot$ Yasuhiro Hashimoto
}

Received: 20 September 2010 / Accepted: 1 February 2011 / Published online: 19 February 2011

(C) The Author(s) 2011. This article is published with open access at Springerlink.com

\begin{abstract}
Objective Cerebrospinal fluid (CSF) shunting can improve symptoms of elderly patients' idiopathic normal pressure hydrocephalus (iNPH). However, adjunctive means for confirming the diagnosis remain unavailable. We have previously reported the specific increase of leucine-rich alpha-2-glycoprotein (LRG) in iNPH CSF, and the present study investigates its potential clinical applications.

Methods We performed CSF tap test (TT) on 90 patients (mean age 73.4 years) and shunting in 52 patients (mean age 73.5 years), evaluating symptom improvement and higher cerebral functions - mini-mental state examination (MMSE) and Frontal Assessment Battery (FAB) before and 12 months after shunting. LRG and tau protein concentrations in TT CSF were simultaneously measured using enzyme-linked immunosorbent assay. We then compared
\end{abstract}

M. Nakajima $(\bowtie) \cdot$ M. Miyajima $\cdot$ I. Ogino $\cdot$ M. Watanabe $\cdot$

H. Miyata $\cdot$ K. L. Karagiozov $\cdot$ H. Arai

Department of Neurosurgery,

Juntendo University School of Medicine,

2-1-1 Hongo, Bunkyo-Ku, Tokyo 113-8421, Japan

e-mail: madoka66@juntendo.ac.jp

\section{Y. Hagiwara}

Department of Pathology and Oncology,

Juntendo University School of Medicine,

Tokyo, Japan

\section{Y. Hagiwara $\cdot$ T. Segawa $\cdot$ K. Kobayashi}

Immuno-Biological Laboratories,

5-1 Aramachi,

Takasaki-Shi, Gunma 370-0831, Japan

\section{Y. Hashimoto}

Department of Biochemistry, School of Medicine,

Fukushima Medical University,

1 Hikarigaoka,

Fukushima-shi, Fukushima 960-1295, Japan the predictive value of these concentrations with TT results regarding successful shunting outcomes.

Results Positive combinations of TT and LRG concentrations of $67 \mathrm{ng} / \mathrm{ml}$ or higher, gave $81.6 \%$ sensitivity and $78.6 \%$ specificity. Therefore we used LRG $(67 \mathrm{ng} / \mathrm{ml})$ and tau $(200 \mathrm{pg} / \mathrm{ml})$ cut-off values, dividing patients into four groups. In group A (LRG $\geq 67 \mathrm{ng} / \mathrm{ml}$ and tau $<200 \mathrm{pg} / \mathrm{ml}$ ) 31 of 34 patients $(91.2 \%)$ had a positive TT and all operated 22 patients were shunt responders. Dementia MMSE and FAB scores in them increased from a baseline of 22.05(SE $\pm 0.96)$ to $25.65( \pm 0.85)$ and $11.38( \pm 0.68)$ to $13.08( \pm 0.57)$ respectively. In group $\mathrm{B},(\mathrm{LRG} \geq 67 \mathrm{ng} / \mathrm{ml}$ and tau $\geq 200 \mathrm{pg} /$ $\mathrm{ml})$, the mean MMSE score increased from $17.62( \pm 2.03)$ to $21.62( \pm 1.96)$, and the FAB decreased slightly from 9.25 $( \pm 1.15)$ to $10.5( \pm 1.59)$, without improvement beyond the range of dementia. In group $\mathrm{C},(\mathrm{LRG}<67 \mathrm{ng} / \mathrm{ml}$, tau $<$ $200 \mathrm{pg} / \mathrm{ml}$ ), the mean MMSE score improved from 22.06 $( \pm 1.25)$ to $24.29( \pm 1.23)$ and the FAB score improved slightly from $12.0( \pm 0.72)$ to $12.87( \pm 0.72)$. Finally, in group D, $(\mathrm{LRG}<67 \mathrm{ng} / \mathrm{ml}, \operatorname{tau} \geq 200 \mathrm{pg} / \mathrm{ml})$, there was almost no improvement in MMSE score

Conclusions A combination of positive TT and biomarkers quantification such as LRG and tau protein, can reliably predict shunting outcome in iNPH patients.

Keywords Leucine-rich alpha-2-glycoprotein · Tau protein - Idiopathic normal pressure hydrocephalus . Cerebrospinal fluid. Shunt placement

\section{Introduction}

The diagnosis of idiopathic normal pressure hydrocephalus (iNPH) in elderly patients is based on the presence of symptoms that include gait disturbance, dementia, and 
urinary incontinence $[1,11,12,25,26]$. These symptoms are also present in numerous neurodegenerative disorders, including Alzheimer's disease (AD), progressive supranuclear palsy (PSP), and Parkinson's disease. iNPH is classically regarded as one of the reversible dementias. However, the results of shunting are often unsatisfactory, with greater improvement encountered in early disease and when memory deficit is only mild or absent [27].

With careful diagnostic evaluation, positive outcome after shunt surgery may reach as much as $75-87 \%[9,10$, $13,33,36,38]$. To date, adjunctive tests for confirming the diagnosis of iNPH are not unavailable. Cerebrospinal fluid (CSF)-based diagnosis of $\mathrm{AD}$ includes the measurement of $\beta$-amyloid 1-42 (A $\beta 1-42)$ and total tau (t-tau) protein levels $[4,20,32]$. For the diagnosis of mild cognitive impairment (MCI), AD and frontotemporal lobe degeneration (FTLD), the CSF biomarkers $A \beta 42, A \beta 40$, t-tau and phosphorylated tau (p-tau) have been reported to be most useful [7, 19]. It has been estimated that the measurement of amyloid $\beta$ and p-tau levels in the CSF exhibits greater than $85 \%$ sensitivity in the diagnosis of $\mathrm{AD}$ [32].

In a recent study using proteome analysis of CSF in iNPH patients, we reported a significant increase in the levels of leucine-rich alpha-2-glycoprotein (LRG) in iNPH patients compared to a control group [23], suggesting that LRG may be a useful biomarker for iNPH diagnosis.

LRG was isolated from human serum by Haupt and Baundner in 1977 [14] and its amino acid sequence was determined in 1985. The LRG consists of 312 amino acid residues, 66 of which are leucines. This protein contains eight repeating consensus sequences, each of which consists of 24 amino acid residues and exhibits a periodic pattern in the occurrence of leucine, proline, and asparagines. This consensus sequence, termed the leucine-rich repeat (LRR), has now been found in over 55,000 sequences in the Pfam database of protein alignments [24, 37]. In the serum, it has been reported that LRG could be a marker of granulocytic differentiation and its expression was up-regulated during neutrophil differentiation [31].

The human LRG gene localizes to chromosome 19p13.3 and its protein is known to exist in the extracellular space. LRG is co-expressed with transforming growth factor $\beta \mathrm{I}$ type II receptor (TGF $\beta$ R-II)[22] and the LRG amino acid sequence contains a putative membrane-binding region, thus suggesting potential binding with TGF $\beta R$-II on the cell surface. LRG is thought to bind to collagen and fibronectin, and some authors believe that LRG also binds to TGF- $\beta$ through collagen [22].

In the current study, we report the establishment of a novel procedure for simultaneously measuring levels of LRG and total tau protein [21], a marker of neuronal degeneration in the CSF. We then compare these levels with tap test results and successful shunt outcomes.

\section{Materials and methods}

Patients and sample collection

This study was conducted over a period of 36 months between January 2006 and December 2008 on consecutive, unselected admissions to our program for iNPH treatment patients with clinically suspected iNPH $[28,35]$. The iNPH was clinically diagnosed in these patients according to the standard classic triad of gait impairment, urinary incontinence and impaired mental function, supported by ventricular dilatation and dilatation of Sylvian fissures, and narrowing of sulci and subarachnoid spaces over the high convexity without significant cerebral atrophy on CT or MRI. Patients with secondary NPH (e.g., following meningitis, hemorrhage, brain tumor, or trauma) were not included in this study. A tap test involving the removal of $30 \mathrm{ml}$ of CSF with an 18 gauge lumbar puncture needle was performed in 90 patients (53 men, 37 women; mean age 73.4 years; range: 57 to 86 years). Tap test evaluation criteria were consistent with Japanese guidelines for iNPH $[17,18]$ within 1 week after removal of CSF, and were deemed positive on any of the following findings: (1) improvement of any item on the "Japanese normal pressure hydrocephalus grading scale revised" (JNPHGS-R)[28] (Table 1), (2) $\geq 10 \%$ improvement on the $3-\mathrm{m}$ up-and-go test or $(3) \geq$ three-point

Table 1 Grading scale for normal pressure hydrocephalus (NPH) ${ }^{\mathrm{a}}$

\begin{tabular}{ll}
\hline Grade & Definition \\
\hline Gait disturbance & \\
0 & Normal \\
1 & Unstable, but independent gait \\
2 & Walking with one cane \\
3 & Walking with two canes or a walker frame \\
4 & Walking not possible \\
Dementia & \\
0 & Within normal range \\
1 & No apparent dementia but apathetic \\
2 & Socially dependent but independent at home \\
3 & Partially dependent at home \\
4 & Totally dependent \\
Urinary incontinence \\
0 & Absent \\
1 & Absent but with pollakisuria or urinary urgency \\
2 & Sometimes at night \\
3 & Sometimes even during the day \\
4 & Frequent
\end{tabular}

a Established by the Research Committee on Intractable Hydrocephalus, Ministry of Health and Welfare of Japan, 1996. The grades of gait disturbance, dementia, and urinary incontinence are added to obtain the total grade, ranging from 0 to 12 . (Mori et al. From Ref. 23) 
improvement on the Mini Mental State Examination (MMSE)[8]. LRG and total tau protein levels were simultaneously measured in tap test CSF samples. Lumbar puncture was performed in the morning under standard condition. A 10-ml CSF sample was collected and gently mixed to avoid gradient effects. All CSF samples with $>500$ erythrocytes $/ \mu 1$ were excluded. All CSF samples were centrifuged to remove cells and debris, aliquoted, and stored at $-80^{\circ} \mathrm{C}$ pending biochemical analysis. Total tau was measured by sandwich ELISA (Innotest hTAU-Ag; Innogenetics, Ghent, Belgium). [30] Nishimura et al. suggest that the appropriate borderline should be $200-400 \mathrm{pg} / \mathrm{ml}$ because $91.4 \%$ of AD cases had a level of more than $200 \mathrm{pg} / \mathrm{ml}$ and $100 \%$ of neurological control group subjects had a level of less than $400 \mathrm{pg} / \mathrm{ml}$. The tau protein kit recommends a cut-off value of clinical significance at $200 \mathrm{pg} / \mathrm{ml}$ of tau in the CSF, with a sensitivity and specificity for total tau 0.914 and 0.521 , respectively. In the present study, the cut-off value was set at $200 \mathrm{pg} / \mathrm{ml}$ to rule out neurodegenerative diseases, mainly AD.

The LRG antibody was co-developed with ImmunoBiological Laboratories Co., Ltd. (IBLC) in order to prepare a sandwich ELISA kit (Human LRG Assay Kit-IBL).

Informed consent was obtained from families prior to shunt placement for the 52 patients (33 men, 19 women; mean age 73.5 years; range $57-86$ years) who demonstrated a positive tap test. Lumboperitoneal shunts (LPS) or ventriculoperitoneal shunts (VPS) were utilized and adjustable valves were used in all patients (Cylindrical Valve with Prechamber ${ }^{\circledR}$ No.82-3110 for VPS and In-Line Valve with SIPHONGUARD ${ }^{\circledR}$ No.82-3832 for LPS, CCodman-Hakim, Johnson \& Johnson, Raynham, MA).

We evaluated symptom improvements (gait disturbance, urinary incontinence) and higher cerebral functions, MMSE and frontal assessment battery; FAB [6]. Surgical outcome was evaluated 12 months post-operatively. A shunt responder (SR) was defined as $a \geq 1$-grade improvement on the JNPHGS-R. MRI follow-up was done 3 months, 6 months, and 12 months after the shunt. If a patient had not improved clinically and the ventricular system had not decreased in size at the re-examination, the shunt was tested by radionuclide shuntography and was surgically corrected if malfunctioning. In case of subsequent shunt surgery after shunt replacement caused by dysfunction, values obtained 12 months after the latest operation were used as post-operative variables.

The study was approved by the ethics committee of Juntendo University. All patients included in the study, or their relatives, gave informed consent to their participation.

\section{Statistical analysis}

All statistical analyses in clinical studies were performed with the Statistical Package of the Social Sciences (SPSS Version 18.0; Cary, NC, USA).
We calculated the relationship between sensitivity and specificity for SR vS. SNR by ROC curve analysis. The "optimum" cut-off value from the ROC curve was the point at which the sum of sensitivity and specificity was maximal. These calculated protein cut-off values were also used to distinguish SR from the SNR, which were the neurodegenerative type of diseases and other dementia conditions.

The $t$ test was used to investigate differences in demographics and levels of tau, and LRG in the CSF between the two pathologic groups. The difference between the pre- and post-operative values was calculated for each index, and the mean of the differences was calculated as an overall result after shunt surgery. Patients showing mean of difference $>0.05$ were considered improved, which corresponded to the clinical impression in each case. A $p$ value $<$ 0.01 was considered significant.

Preparation of the human LRG assay Kit-IBL

A sandwich ELISA assay was developed to measure CSF, serum/plasma, and urinary LRG levels. A key feature of this portion of the study was the development of specific antibodies directed against LRG. We produced a human LRG (329) antibody directed against an amino acid sequence in the LRG C-terminus (peptide amino acid sequence: AGPEAVKGQTLLAVAKSQ) and a human LRG (162) antibody directed against an amino acid sequence located within close proximity to the N-terminus (peptide amino acid sequence: GLKALGHLD LSGNRLRKL). Each antigenic site was found to be involved in maleimide-activated peptide synthesis with binding to bovine serum thyroglobulin. The antigen $(100 \mu \mathrm{g})$ was then mixed with Freund's complete adjuvant and was used to immunize rabbits both subcutaneously and intradermally. For booster immunization, the antigen $(100 \mu \mathrm{g})$ and Freund's incomplete adjuvant were both injected subcutaneously and intradermally in eight doses at 2-week intervals. The antiserum obtained by immunization was purified on an antigen affinity column prepared by binding the antigen peptide to Activated Thiol Sepharose 4B (GE Healthcare). After adsorption with D-PBS buffer $(\mathrm{pH}$ 7.4), antibodies were eluted using 0.2 M glycine buffer ( $\mathrm{pH}$ 2.5). This procedure provided a highly specific polyclonal antibody.

Measurement of LRG levels using the human LRG assay Kit-IBL

The sandwich ELISA assay was developed using the human LRG (162) and LRG (329) antibodies. The human LRG (162) antibody was diluted in $0.1 \mathrm{M}$ carbonate buffer (2 $\mu \mathrm{g} / 100 \mu \mathrm{l} /$ well), immobilized on ELISA plates and blocked in BSA solution. A human LRG reference standard 
and the samples $(100 \mu \mathrm{l} /$ well $)$ were added and the trapprecoated plates were covered with plate lids and incubated overnight at $4{ }^{\circ} \mathrm{C}$ to select for human LRG in solution. The samples were repeatedly washed in PBS containing $0.05 \%$ Tween 20 and then incubated with the horseradish peroxidase (HRP)-conjugated Fab fragment of the human LRG (329) antibody $(100 \mu \mathrm{l} /$ well $)$ at $37^{\circ} \mathrm{C}$ for $30 \mathrm{~min}$. The labeled Fab fragment is known to bind HRP by the maleimide method and was purified by gel filtration. The samples were then washed in PBS containing $0.05 \%$ Tween 20 and the HRP color substrate tetra methyl benzidine (TMB, $100 \mu \mathrm{l} /$ well) was added. The color reaction was then quenched with $1 \mathrm{~N}$ sulfuric acid and measured at $450 \mathrm{~nm}$ by absorption [i Mark ${ }^{\mathrm{TM}}$ Microplate Reader (Bio-Red(C)].

Assay values were calculated using a calibration curve that had been prepared in advance using a reference product containing a known LRG concentration.

\section{Results}

Total LRG and tau levels in CSF samples obtained from 52 patients who underwent shunt placement were compared between the shunt responder (SR) group, which demonstrated improved symptoms following shunt placement, and the shunt nonresponder (SNR) group, which demonstrated no clinical benefit following shunt placement. LRG levels were found to be significantly higher in the SR group $(96.8 \pm 44.6 \mathrm{ng} / \mathrm{ml}[$ mean $\pm \mathrm{SD}])$ than in the SNR group $(29.2 \pm 35.1 \mathrm{ng} / \mathrm{ml} ; p<0.01)$ (Fig. 1a). Tau protein levels in the CSF did not differ significantly between the SR group $(167.4 \pm 105.4 \mathrm{pg} / \mathrm{ml})$ and the SNR group $(264.9 \pm 209.5 \mathrm{pg} / \mathrm{ml} ; p>0.05)$ (Fig. 1b).

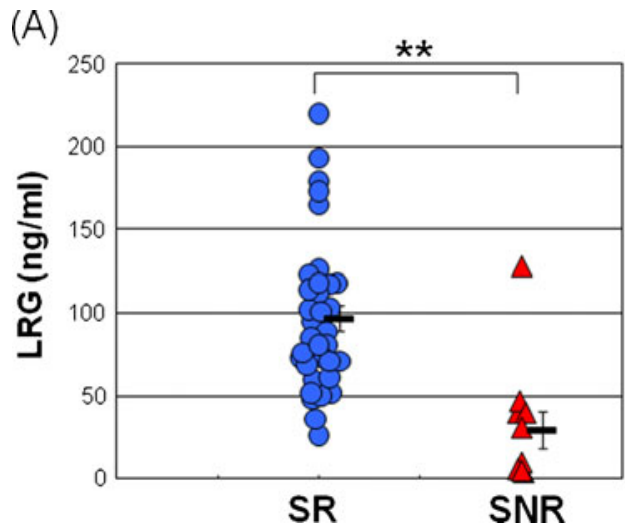

Fig. $1 S R$ shunt responder, $S N R$ shunt nonresponder. Levels of CSF LRG (A), tau protein (B) ratio in studied groups. Each blue circle represents shunt responders and red triangles represent the shunt nonresponder individual. Horizontal lines indicate median values. a Correlation between LRG and SR and SNR. LRG levels were found
Scatter plots were prepared for LRG and tau values in all 90 patients, with LRG on the vertical axis and tau on the horizontal axis (Fig. 2a). As can be observed, many negative tap test patients demonstrated high tau levels, irrespective of whether low or high LRG levels were recorded. A comparison of the tau protein levels identified in the tap test-positive and -negative groups for all 90 patients showed a significant difference between the positive $(186.8 \pm 133.3 \mathrm{pg} / \mathrm{ml})$ and negative group $(331.5 \pm$ $277.6 \mathrm{pg} / \mathrm{ml} ; p<0.05)$. In other words, the determination of CSF tau protein levels could potentially play an adjunctive role in the CSF diagnosis of iNPH using LRG levels. Subsequently, patients were classified into groups based on their LRG and tau protein levels, and their symptom improvement was assessed by the tap test and shunt placement.

The sensitivity and specificity for LRG in CSF for differentiation of SR from SNR were determined by ROC curve analysis (Fig. 3). The optimum cut-off was found at $67 \mathrm{ng} / \mathrm{ml}$. ROC curve analysis with area under the curve (AUC) and SE calculated, 0.792 and 0.078 , respectively. The sensitivity and specificity for LRG are 0.816 and 0.786 , respectively.

Four groups were classified based on these cut-off values and were termed group A (LRG $\geq 67 \mathrm{ng} / \mathrm{ml}$, tau $<200 \mathrm{pg}$ / $\mathrm{ml}$ ), group $B(\mathrm{LRG} \geq 67 \mathrm{ng} / \mathrm{ml}, \mathrm{tau} \geq 200 \mathrm{pg} / \mathrm{ml})$, group C $(\mathrm{LRG}<67 \mathrm{ng} / \mathrm{ml}$, tau $<200 \mathrm{pg} / \mathrm{ml})$ and group $\mathrm{D}(\mathrm{LRG}<$ $67 \mathrm{ng} / \mathrm{ml}, \mathrm{tau} \geq 200 \mathrm{pg} / \mathrm{ml}$ ) (Table 2).

The positive tap test results for each group were: group A31 of 34 patients $(91.2 \%)$; group $\mathrm{B}-15$ of 21 patients (71.4\%); group $\mathrm{C}-15$ of 24 patients $(62.5 \%)$; and group D-6 of 11 patients $(54.2 \%)$ (Table 3). We also evaluated outcome results in the 52 patients who underwent shunt placement in terms of SR or SNR. In the group

(B)

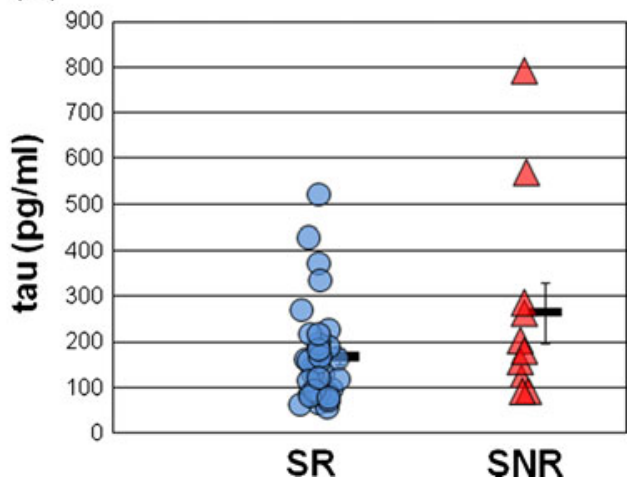

to be significantly higher in the SR group $(96.8 \pm 44.6 \mathrm{ng} / \mathrm{ml}$ [mean \pm $\mathrm{SD}])$ than the SNR group $(29.2 \pm 35.1 \mathrm{ng} / \mathrm{ml} ; * *<0.01)$. b Correlation between tau and SR and SNR. Tau protein levels in the CSF did not significantly differ between the SR group $(167.4 \pm 105.4 \mathrm{pg} / \mathrm{ml})$ and the SNR group $(264.9 \pm 209.5 \mathrm{pg} / \mathrm{ml} ; p>0.05)$ 


\section{a}

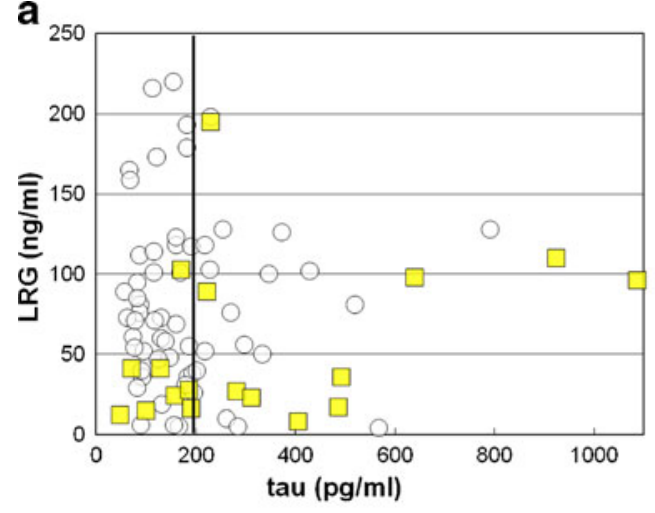

b

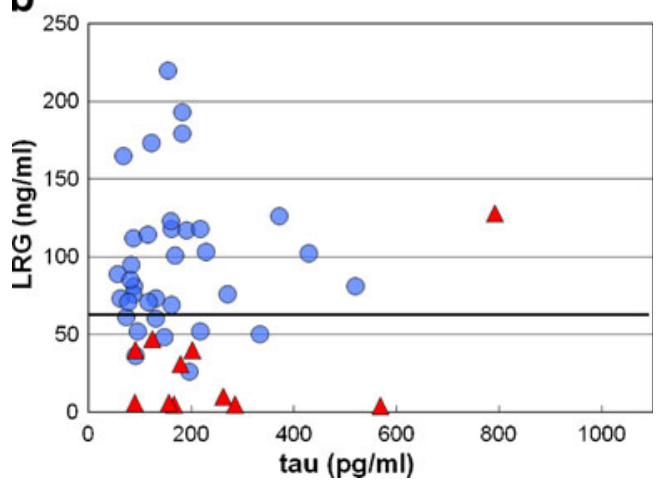

Fig. 2 LRG and total tau protein levels in tap tests 90 cases. a Scatter plot of the CSF LRG and total tau protein levels in 90 patients who underwent tap tests. Each white circle represents tap test-positive patients and the yellow square represents tap test-negative patients. The tau protein kit used in the present study (Innotest hTAU-Ag; Innogenetics) recommends the cut-off value for clinical manifestation at $200 \mathrm{pg} / \mathrm{ml}$ of tau in the CSF (the solid line). b Scatter plot of the CSF LRG and total tau protein levels in 52 patients who underwent shunt replacement. Each white circle represents shunt responders, and the red triangle represents the shunt nonresponder individual. ROC curve analysis indicated that the optimum cut-offs (solid line) for SR vs. SNR was $67 \mathrm{ng} / \mathrm{ml}$ for LRG

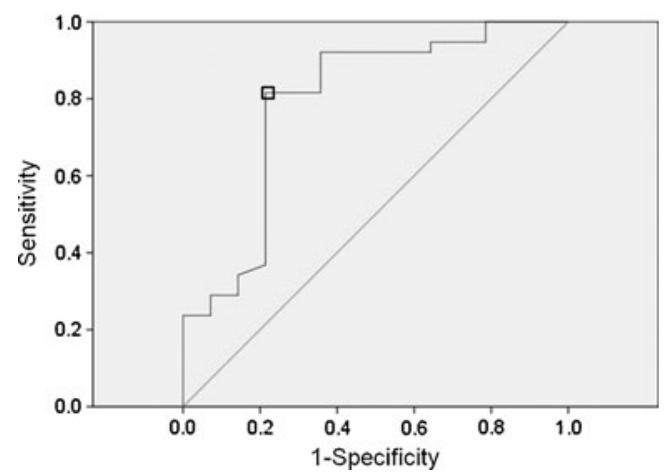

Fig. 3 ROC curve analysis for LRG in CSF for differentiation of SR from SNR. ROC curve analysis with area under the curve (AUC) and SE calculated using Statistical Package for the Social Sciences (SPSS). The cut-off is given for sensitivity+specificity maximized for SR vs. SNR. The optimum cut-off was $67 \mathrm{ng} / \mathrm{ml}$ for LRG(口). AUC and SE are 0.792 and 0.078 , respectively
Table 2 Patient groups according to LRG and TAU levels

\begin{tabular}{lll}
\hline Group & TAU $<200 \mathrm{pg} / \mathrm{ml}$ & TAU $\geq 200 \mathrm{pg} / \mathrm{ml}$ \\
\hline LRG $\geq 67 \mathrm{ng} / \mathrm{ml}$ & A & B \\
LRG $<67 \mathrm{ng} / \mathrm{ml}$ & C & D \\
\hline
\end{tabular}

A - 22 of 22 patients were SR (100\%), in group B - ten of 11 patients were SR $(90.9 \%)$, in group $\mathrm{C}$ - six of 13 patients were SR $(46.2 \%)$ and in group D-two of six patients were SR (33.3\%) (Table 3).

MMSE and FAB tests were performed prior to and 12 months following shunt placement to evaluate the improvement in dementia symptoms. In group $\mathrm{A}$, the mean MMSE and FAB scores at baseline and 12 months markedly improved from 22.05 to $25.65( \pm 0.96)$ and $11.38( \pm 0.68)$ to $13.08( \pm 0.57)$, respectively. In group B, the mean MMSE score improved from $17.62( \pm 2.03)$ to $21.62( \pm 1.96)$ and the FAB improved from $9.25( \pm 1.15)$ to $10.5( \pm 1.59)$, but did not improve beyond the score limits of dementia. In group $\mathrm{C}$, the mean MMSE score improved from $22.06( \pm 1.25)$ to $24.29( \pm 1.23)$ and the FAB score improved slightly from $12.0( \pm 0.72)$ to 12.87 $( \pm 0.72)$. In group $\mathrm{D}$, there was almost no improvement, MMSE score improved from $17.25( \pm 4.55)$ to 17.75 $( \pm 4.50)$ and the FAB improved from $11.33( \pm 1.86)$ to $12.33( \pm 1.20)$ (Table 4).

\section{Discussion}

In the brain of $\mathrm{AD}$ patients, specific structures such as senile plaques and neurofibrillary tangles (NFT) are often seen [34]. NFT comprise structures called paired helical filaments (PHF), and the main components are abnormal phosphate compounds of human tau, a cytoskeleton-related protein in neurons $[15,16]$. In general, human tau is mostly absent from CSF. However, neuron destruction in neurodegenerative diseases such as $\mathrm{AD}$ releases human tau into the CSF [29]. Human tau levels are thus an indicator of nerve degeneration, and can be used to rule out psychiatric disorders unaccompanied by nerve degeneration, such as dementia and depression. Due to ethical considerations, shunt surgery was not performed on patients with a negative tap test (i.e., patients in whom symptoms did not improve by the tap test, an established diagnostic test). Diagnostic sensitivity and specificity in the present study were thus obtained only from a group of patients with a positive tap test. The assessment criterion for the tap test was a reduction of $\geq 10 \%$ in walk time after tapping. However, with this test, walk time can shorten because subjects are instructed to walk in a charge-like manner, and 
Table 3 Evaluation of tap test and shunt response by group

\begin{tabular}{lllll}
\hline & $\begin{array}{l}\text { Group A } \\
\text { LRG } \geq 67 \mathrm{ng} / \mathrm{ml}, \\
\text { tau }<200 \mathrm{pg} / \mathrm{ml}\end{array}$ & $\begin{array}{l}\text { Group B } \\
\mathrm{LRG} \geq 67 \mathrm{ng} / \mathrm{ml}, \\
\text { tau } \geq 200 \mathrm{pg} / \mathrm{ml}\end{array}$ & $\begin{array}{l}\text { Group C } \\
\mathrm{LRG}<67 \mathrm{ng} / \mathrm{ml}, \\
\text { tau }<200 \mathrm{pg} / \mathrm{ml}\end{array}$ & $\begin{array}{l}\text { Group D } \\
\mathrm{LRG}<67 \mathrm{ng} / \mathrm{ml}, \\
\text { tau } \geq 200 \mathrm{pg} / \mathrm{ml}\end{array}$ \\
\hline $\begin{array}{l}\text { Tap test-positive }(n=90) \\
\text { Shunt responder }(n=52)\end{array}$ & $\begin{array}{l}31 / 34(91.2 \%) \\
22 / 22(100 \%)\end{array}$ & $\begin{array}{l}15 / 21(71.4 \%) \\
10 / 11(90.9 \%)\end{array}$ & $\begin{array}{l}15 / 24(62.5 \%) \\
6 / 13(46.2 \%)\end{array}$ & $6 / 11(54.2 \%)$ \\
\hline
\end{tabular}

the cue effect $[2,3]$ can make patients consciously improve their time, resulting in numerous false-positive cases. As far as the diagnostic value of a positive tap test is concerned, making the definition stricter by using the modified Rankin scale [5] lowers the sensitivity, but increases the specificity. The diagnostic standards for the tap test in the present study were not very strict.

In our study, levels of $L R G \geq 67 \mathrm{ng} / \mathrm{ml}$ and tau $<200 \mathrm{pg} / \mathrm{ml}$; group A were associated with increased symptom improvement rates following shunt placement. The higher diagnostic rate obtained using our procedure, which requires only small amounts of CSF, suggests that this method may be useful for diagnosis in patients with lumbar spine degeneration or scoliosis, where lumbar puncture is often difficult, and the inconveniences of the tap test or lumbar drainage can be avoided.

In addition, the findings outlined in our study may also prove useful for predicting the optimal time for shunt surgery in iNPH patients. Among the patients that demonstrated high LRG levels ( $\geq 67 \mathrm{ng} / \mathrm{ml})$ in the CSF, those that also had a negative tap test tended to demonstrate high tau protein levels (tau $\geq 200 \mathrm{pg} / \mathrm{ml}$ ). In group A (low tau levels; tau $<200 \mathrm{pg} / \mathrm{ml}$ ), only three of 34 patients also had a negative tap test. Of the 22 who were positive and received shunt placement, all 22 showed improvement in their symptoms. In group B (high tau levels), six of the 21 patients had a negative tap test. Of those who were positive and had shunt placement, only one patient failed to demonstrate improvement. In other words, even when
LRG levels in CSF are high, the SNR rate remains low if tau protein levels are also high.

It is well established that the tau protein is a marker for neuronal cell death [29]. In group $B$ ( $L R G \geq 67 \mathrm{ng} / \mathrm{ml}$, tau $\geq$ $200 \mathrm{pg} / \mathrm{ml}$ ), this indicated either a more advanced iNPH with irreversible neurologic symptoms or co-existing neurodegenerative disorders like a AD. Based on our findings, the prognosis for symptom improvement following shunt placement is greater in the early stages of iNPH before severe neuronal loss occurs, making the perspective for improvement of symptoms better in group A, where CSF tau protein levels were less than $200 \mathrm{pg} / \mathrm{ml}$. In group $\mathrm{D},(\mathrm{LRG}<67 \mathrm{ng} / \mathrm{ml}, \mathrm{tau} \geq 200 \mathrm{pg} / \mathrm{ml})$, six patients achieved a positive tap test, although four patients $(66.6 \%)$ demonstrated no symptomatic improvement after shunt placement. Thus, in group D, where the tap test false-positive rate was high, progression to neurodegenerative disease is likely and shunt placement should not be considered beneficial.

\section{Conclusions}

In conclusion, LRG levels in the CSF are a potential biomarker for the diagnosis of iNPH. The combination of a tap test, excluding a false-positive tap test, and the measurement of LRG and tau protein levels in the CSF may accurately predict a group of iNPH patients in whom shunt placement is likely to improve gait disturbance and dementia.
Table 4 Cognitive outcomes (52 patients with shunt placement)

MMSE mini mental state examination, $F A B$ frontal association battery

$S E$ standard error, $C C$ correlation coefficient $P$ value; $p<0.05^{*}, p<0.01^{* *}$

\begin{tabular}{lllll}
\hline & Group A & Group B & Group C & Group D \\
\hline MMSE pre $( \pm$ SE $)$ & $22.05( \pm 0.96)$ & $17.62( \pm 2.03)$ & $22.06( \pm 1.25)$ & $17.25( \pm 4.55)$ \\
12 months after $( \pm$ SE $)$ & $25.65( \pm 0.85)$ & $21.62( \pm 1.96)$ & $24.29( \pm 1.23)$ & $17.75( \pm 4.50)$ \\
Mean of difference $( \pm$ SE) & $3.6( \pm 0.76)$ & $4.0( \pm 1.25)$ & $2.23( \pm 0.55)$ & $0.5( \pm 0.87)$ \\
CC & 0.656 & 0.806 & 0.905 & 0.982 \\
$p$ value & $* *$ & $* *$ & $* *$ & \\
FAB pre $( \pm$ SE $)$ & $11.38( \pm 0.68)$ & $9.25( \pm 1.15)$ & $12.0( \pm 0.72)$ & $11.33( \pm 1.86)$ \\
12 months after $( \pm$ SE $)$ & $13.08( \pm 0.57)$ & $10.5( \pm 1.59)$ & $12.87( \pm 0.72)$ & $12.33( \pm 1.20)$ \\
post - pre mean $( \pm$ SE $)$ & $1.69( \pm 0.57)$ & $1.25( \pm 0.86)$ & $0.87( \pm 0.41)$ & $1.0( \pm 2.0)$ \\
CC & 0.6 & 0.852 & 0.836 & 0.573 \\
$p$ value & $*$ & & & \\
\hline
\end{tabular}


Acknowledgements This work was partly supported by a Research Grant from the Ministry of Health, Labor and Welfare of Japan (2008Nanchi-17) and the Juntendo University Research Institute for Diseases of Old Age.

\section{Conflicts of interest None}

Open Access This article is distributed under the terms of the Creative Commons Attribution Noncommercial License which permits any noncommercial use, distribution, and reproduction in any medium, provided the original author(s) and source are credited.

\section{References}

1. Adams RD, Fisher CM, Hakim S, Ojemann RG, Sweet WH (1965) Symptomatic occult hydrocephalus with "normal" cerebrospinalfluid pressure. A treatable syndrome. N Engl J Med 273:117-126

2. Baker K, Rochester L, Nieuwboer A (2007) The immediate effect of attentional, auditory, and a combined cue strategy on gait during single and dual tasks in Parkinson's disease. Arch Phys Med Rehabil 88:1593-1600

3. Baker K, Rochester L, Nieuwboer A (2008) The effect of cues on gait variability-reducing the attentional cost of walking in people with Parkinson's disease. Parkinsonism Relat Disord 14:314-320

4. Bian H, Van Swieten JC, Leight S, Massimo L, Wood E, Forman M, Moore P, de Koning I, Clark CM, Rosso S, Trojanowski J, Lee VM, Grossman M (2008) CSF biomarkers in frontotemporal lobar degeneration with known pathology. Neurology 70:1827-1835

5. Burn JP (1992) Reliability of the modified Rankin scale. Stroke 23:438

6. Dubois B, Slachevsky A, Litvan I, Pillon B (2000) The FAB: a Frontal Assessment Battery at bedside. Neurology 55:1621-1626

7. Ewers M, Buerger K, Teipel SJ, Scheltens P, Schroder J, Zinkowski RP, Bouwman FH, Schonknecht P, Schoonenboom NS, Andreasen N, Wallin A, DeBernardis JF, Kerkman DJ, Heindl B, Blennow K, Hampel H (2007) Multicenter assessment of CSFphosphorylated tau for the prediction of conversion of MCI. Neurology 69:2205-2212

8. Folstein MF, Folstein SE, McHugh PR (1975) Mini-mental state. A practical method for grading the cognitive state of patients for the clinician. J Psychiatr Res 12:189-198

9. Graff-Radford NR, Godersky JC (1986) Normal-pressure hydrocephalus. Onset of gait abnormality before dementia predicts good surgical outcome. Arch Neurol 43:940-942

10. Graff-Radford NR, Godersky JC (1989) Symptomatic congenital hydrocephalus in the elderly simulating normal pressure hydrocephalus. Neurology 39:1596-1600

11. Hakim S, Adams RD (1965) The special clinical problem of symptomatic hydrocephalus with normal cerebrospinal fluid pressure. Observations on cerebrospinal fluid hydrodynamics. J Neurol Sci 2:307-327

12. Hakim S, Venegas JG, Burton JD (1976) The physics of the cranial cavity, hydrocephalus and normal pressure hydrocephalus: mechanical interpretation and mathematical model. Surg Neurol 5:187-210

13. Hashimoto M, Ishikawa M, Mori E, Kuwana N, Sinphoni Group AF (2010) Diagnosis of idiopathic normal pressure hydrocephalus is supported by MRI-based scheme: a prospective cohort study. Cerebrospinal Fluid Res 7:18

14. Haupt H, Baudner S (1977) Isolation and characterization of an unknown, leucine-rich 3.1-S-alpha2-glycoprotein from human serum (author's transl). Hoppe-Seylers Z Physiol Chem 358:639-646

15. Iqbal K, Grundke-Iqbal I (2008) Alzheimer neurofibrillary degeneration: significance, etiopathogenesis, therapeutics and prevention. J Cell Mol Med 12:38-55

16. Iqbal K, Liu F, Gong CX, Alonso Adel C, Grundke-Iqbal I (2009) Mechanisms of tau-induced neurodegeneration. Acta Neuropathol 118:53-69

17. Ishikawa M (2004) Clinical guidelines for idiopathic normal pressure hydrocephalus. Neurol Med Chir (Tokyo) 44:222-223

18. Ishikawa M, Hashimoto M, Kuwana N, Mori E, Miyake H, Wachi A, Takeuchi T, Kazui H, Koyama H (2008) Guidelines for management of idiopathic normal pressure hydrocephalus. Neurol Med Chir (Tokyo) 48:S1-S23

19. Kapaki E, Paraskevas GP, Papageorgiou SG, Bonakis A, Kalfakis N, Zalonis I, Vassilopoulos D (2008) Diagnostic value of CSF biomarker profile in frontotemporal lobar degeneration. Alzheimer Dis Assoc Disord 22:47-53

20. Kapaki EN, Paraskevas GP, Tzerakis NG, Sfagos C, Seretis A, Kararizou E, Vassilopoulos D (2007) Cerebrospinal fluid tau, phospho-tau181 and beta-amyloid1-42 in idiopathic normal pressure hydrocephalus: a discrimination from Alzheimer's disease. Eur J Neurol 14:168-173

21. Kudo T, Mima T, Hashimoto R, Nakao K, Morihara T, Tanimukai H, Tsujio I, Koike Y, Tagami S, Mori H, Nakamura Y, Tanaka T, Mori K, Takeda M (2000) Tau protein is a potential biological marker for normal pressure hydrocephalus. Psychiatry Clin Neurosci 54:199-202

22. Li X, Miyajima M, Jiang C, Arai H (2007) Expression of TGFbetas and TGF-beta type II receptor in cerebrospinal fluid of patients with idiopathic normal pressure hydrocephalus. Neurosci Lett 413:141-144

23. Li X, Miyajima M, Mineki R, Taka H, Murayama K, Arai $\mathrm{H}$ (2006) Analysis of potential diagnostic biomarkers in cerebrospinal fluid of idiopathic normal pressure hydrocephalus by proteomics. Acta Neurochir (Wien) 148:859-864, discussion 864

24. Matsushima N, Tanaka T, Enkhbayar P, Mikami T, Taga M, Yamada K, Kuroki Y (2007) Comparative sequence analysis of leucine-rich repeats (LRRs) within vertebrate Toll-like receptors. BMC Genomics 8:124

25. McGirt MJ, Woodworth G, Coon AL, Thomas G, Williams MA, Rigamonti D (2005) Diagnosis, treatment, and analysis of longterm outcomes in idiopathic normal-pressure hydrocephalus. Neurosurgery 57:699-705, discussion 699-705

26. McGirt MJ, Woodworth G, Coon AL, Thomas G, Williams MA, Rigamonti D (2008) Diagnosis, treatment, and analysis of longterm outcomes in idiopathic normal-pressure hydrocephalus. Neurosurgery 62(Suppl 2):670-677

27. Meier U, Miethke C (2003) Predictors of outcome in patients with normal-pressure hydrocephalus. J Clin Neurosci 10:453-459

28. Mori K (2001) Management of idiopathic normal-pressure hydrocephalus: a multiinstitutional study conducted in Japan. J Neurosurg 95:970-973

29. Morihara T, Kudo T, Ikura Y, Kashiwagi Y, Miyamae Y, Nakamura Y, Tanaka T, Shinozaki K, Nishikawa T, Takeda M (1998) Increased tau protein level in postmortem cerebrospinal fluid. Psychiatry Clin Neurosci 52:107-110

30. Nishimura T, Takeda M, Nakamura Y, Yosbida Y, Arai H, Sasaki H, Shouji M, Hirai S, Khise K, Tanaka K, Hamamoto M, Yamamoto H, Matsubayashi T, Urakami K, Adachi Y, Nakashima K, Toji H, Nakamura S, Yoshida H (1998) Basic and clinical studies on the measurement of tau protein in cerebrospinal fluid as a biological marker for Alzheimer's disease and related disorders: multicenter study in Japan. Methods Find Exp Clin Pharmacol 20:227-235 
31. O'Donnell LC, Druhan LJ, Avalos BR (2002) Molecular characterization and expression analysis of leucine-rich alpha2glycoprotein, a novel marker of granulocytic differentiation. J Leukoc Biol 72:478-485

32. Olsson A, Vanderstichele H, Andreasen N, De Meyer G, Wallin A, Holmberg B, Rosengren L, Vanmechelen E, Blennow K (2005) Simultaneous measurement of beta-amyloid(1-42), total tau, and phosphorylated tau (Thr181) in cerebrospinal fluid by the xMAP technology. Clin Chem 51:336-345

33. Pujari S, Kharkar S, Metellus P, Shuck J, Williams MA, Rigamonti D (2008) Normal pressure hydrocephalus: long-term outcome after shunt surgery. J Neurol Neurosurg Psychiatry 79:1282-1286

34. Querfurth HW, LaFerla FM (2010) Alzheimer's disease. N Engl J Med 362:329-344

35. Sasaki M, Honda S, Yuasa T, Iwamura A, Shibata E, Ohba H (2008) Narrow CSF space at high convexity and high midline areas in idiopathic normal pressure hydrocephalus detected by axial and coronal MRI. Neuroradiology 50:117-122

36. Savolainen S, Hurskainen H, Paljarvi L, Alafuzoff I, Vapalahti M (2002) Five-year outcome of normal pressure hydrocephalus with or without a shunt: predictive value of the clinical signs, neuropsychological evaluation and infusion test. Acta Neurochir (Wien) 144:515-523, discussion 523

37. Shirai R, Hirano F, Ohkura N, Ikeda K, Inoue S (2009) Upregulation of the expression of leucine-rich alpha(2)-glycoprotein in hepatocytes by the mediators of acute-phase response. Biochem Biophys Res Commun 382:776-779

38. Wikkelso C, Andersson H, Blomstrand C, Lindqvist G, Svendsen P (1986) Normal pressure hydrocephalus. Predictive value of the cerebrospinal fluid tap-test. Acta Neurol Scand 73:566-573

\section{Comments}

This paper deals with an intriguing and certainly clinically relevant topic: the possibility of predicting shunting outcome in iNPH patients, using a combination of positive TT and CSF levels of LRG and tau proteins. The combination of such biomarkers, based on a robust cut-off, clearly clustered four groups with specific cognitive outcome as measured by MMSE and FAB changes, 12 months after shunting. The statistical analysis is well conducted and the results are sound. More investigational work is clearly needed in this field.

Domenico d'Avella

Mario Ermani

Padova, Italy 